\title{
Elements that Establish a Healthy Doctor Patient Relationship
}

\author{
Article by Kim Near ${ }^{1}$, Sayanth Raj $^{1}$, Niharika Anand ${ }^{1}$ \\ ${ }^{1} M D$, Texila American University, Guyana, South America
}

\begin{abstract}
Background: The doctor patient relationship is the keystone of our health care system. But in modern medicine, there is very little credit given to this relationship. The degradation of the doctor patient relationship has led to unsatisfied patients, frustrated doctors and overall diminution in the quality of health care.

Objective: The aim of this study is to emphasize the importance of a good doctor patient relationship.

Method: The present study, upon review of several articles, discusses the components of a good doctor patient relationship, and summarizes it into five major categories. From the articles researched, below are a comprehension of the collective information gathered and presented in a redefined, organised manner.

Conclusions: The five main categories discussed include: First impressions, mannerisms, communication skills, professionalism qualities, and collaborative decision making. The study also talks about how these five components are integrated, and how it effects the doctor patient relationship, leading to better therapeutic outcomes in patients and long-term job satisfaction in doctors.
\end{abstract}

Keywords: doctor patient relationship, first impressions, mannerisms, communication skills, professionalism qualities, collaborative decision.

\section{Introduction}

The doctor-patient relationship is a central part of health care and the practice of medicine. It forms one of the foundations of contemporary medical ethics. Since the time of Hippocrates, this special relationship has received much philosophical and literary attention. Since then, medicine has come a long way in recognizing the effect and importance of this relationship. However, despite emphasis on the need for curricula that foster patient-centred attitudes among medical students, data suggest that students in later years of medical school have attitudes that are more doctor-centred or paternalistic compared to students in earlier years. (Paul Haidet et al, 2002).

A doctor's communication and interpersonal skills encompass the ability to gather information in order to facilitate accurate diagnosis, counsel appropriately, give therapeutic instructions, and establish caring relationships with patients. These are the core clinical skills in the practice of medicine, with the ultimate goal of achieving the best outcome and patient satisfaction, which are essential for the effective delivery of health care. The ultimate objective of any doctor-patient communication is to improve the patient's health and medical care. The Balint Society, founded in the UK in 1969, is a supportive and collaborative medical organization of clinicians and teachers who emphasize the importance of the use of emotion and personal understanding in the doctor's work and the therapeutic potential of the doctorpatient relationship. Nonetheless, the worrying fact remains that with the rapid modernisation of health care, these principles are less focused upon. (Mechanic D et al).

According to a study in the journal BMJ Open, patients whose doctors listen to and respect them are more likely to disclose important information, stick with treatment regimens and get important health screenings. As the authors noted, "the weight of evidence across different areas of health care indicates that patient experience is clinically important."

Doctors tend to overestimate their abilities in communication. Studies on doctor-patient communication have demonstrated patient discontent even when many doctors considered the communication adequate or even excellent. Tongue et al reported that $75 \%$ of the orthopaedic surgeons surveyed believed that they communicated satisfactorily with their patients, but only $21 \%$ of the patients reported satisfactory communication with their doctors. 
Effective doctor-patient communication is determined by the doctors' "bedside manner," which patients judge as a major indicator of their doctors' general competence.

According to a study published in the journal Health Services Research, the relationship between a physician and their patient is the key to high patient engagement. Some major aspects include:

- The quality of the patient-physician relationship - especially how well the doctor communicates in the office.

- The amount of respect and fairness patients felt they received.

- The frequency of patient-physician communication outside of the office (through email or phone).

The study found that patient communication was one of the most critical elements of success: for every one unit increase in the quality of interpersonal exchanges, patients reported a 10 unit increase in their overall engagement levels.

Good doctor-patient communication has the potential to help regulate patients' emotions, facilitate comprehension of medical information, and allow for better identification of patients' needs, perceptions, and expectations. (Kelly JM et al, 2014) Patients' agreement with the doctor about the nature of the treatment and need for follow-up is strongly associated with their recovery. (Levinson $W$ et al).

A good doctor patient relationship is not only crucial for the patient, but also beneficial for the doctor. Satisfied patients are less likely to lodge formal complaints or initiate malpractice complaints. Satisfied patients are advantageous for doctors in terms of greater job satisfaction, less work-related stress, and reduced burnout.

In the modern word of healthcare, everyone is more inclined to focus on the academic side of medicine. Even while choosing a medical school, students tend to select the school which have a greater academic reputation. Hence, medical schools side-line the importance of the other aspects of working in healthcare, such as communication skills, empathy, and doctor patient relationships. The lack of social and communication skills in a doctor had caused a rift between professionals and patients, leading to withholding of information, mistrust from both ends, and ultimately, misdiagnosis and inappropriate treatment. All this is a vicious cycle, which does not help anybody. The few opportunities that are presented to upcoming doctors to hone their social and communication skills are also not holistic.

In this article, we aim to tackle these problems and emphasize the need and importance of a good doctor patient relationship. We will also discuss the components that effect this relationship and provide a holistic approach to establishing this relationship.

\section{Methods}

Various articles were derived from open source journals through Pubmed, Research Gate and Google Scholar. These articles were intensely reviewed by the authors and consolidated below. This review is a narrative review, where selected studies are compared and summarized on the basis of the author's experience, existing theories and models. Results are based on a qualitative rather than a quantitative level. All article relevant to the topic were considered for review. Inclusion criteria include articles that present evidence-based views and are published in an indexed journal. Articles which are based on theory, and thereby lacking any statistical evidence were excluded.

\section{Results}

The benefits of building a good patient doctor relationship ensures good trust, open communication, collaboration as well as good adherence to advice and medical treatment that the doctor is being advised to the patient (Woolf Steven et al, 1999) In addition this helps build loyalty as well as many referrals from the patient where they are much more likely to return and recommend their families and friends to see the doctor, which increases the doctor's demand (Emanuel EJ et al, 1992).

Alternatively, a bad patient doctor relationship will result in the patient being closed off and not revealing all of the information that they may not think is relevant, as well as less adherences to intervention and treatment recommended by the doctor (Cathy Charles et al, 1999). In addition, it creates a poor satisfaction as well as a higher rate of being sued. The patient is also more likely to not return for a follow up appointment and find another doctor (Woolf Steven et al, 1999). 
However, the characteristics of a good patient doctor relationship comprise of many components and many factors (The Social Medicine Reader). This article will collaborate the different research components into a simplified digestible manner.

From the articles researched, below are a comprehension of the collective information gathered, presented in a redefined organised manner. In doing so the topics discussed are summarised into five main categories, which also comprise of many sub categories. The five main categories discussed include: First impressions, mannerisms, communication skills, professionalism qualities, and collaborative decision making.

It should be pointed out that some of attributes and skills mentioned in the sub categories overlap into other categories and to ensure the most accurate and reliable information presented, there will be some cross overs to not limit the information presented as well as ensuring the most accurate collection of research to be presented in a well-rounded comprehensive manner (Emanuel EJ et al, 1999).

\section{First impression}

With first impression, this refers to how a patient views the doctor the first time they see the doctor (Karen Sue, 2011). The first encounter of the patient with the doctor instantly forms an impression about the doctor's professionalism, credibility's, and abilities which shape how well the patient will decide to interact with the doctor as well as trust their advice and follow the doctor's advice (Mary Klein Buller, 1987).

This is one of the fastest ways for a doctor to generate a good lasting impression which helps build a healthy doctor patient relationship and establish trust, open communication and adherence to the recommendations by the doctor (Shakaib U Rehman et al, 2005).

Alternatively, a bad first impression, although can be changed over time in some cases, with a lot of work, it sometimes is also impossible to recover especially when there are a lot of competition doctors in the community (Karen Sue, 2011).

First impression is generally believed to be the first time someone sees you, in this case being the first time the patient sees the doctor although this is true, it actually starts before this with the very first time the patient gets any exposure to the doctor (Carol Teutsh). This includes things like how professional and simple it is to navigate on the doctor's website and find useful information, how welcoming, pleasant, the appearance of the secretary and friendly the secretary is when the patient tries to call to make an appointment or how the secretary greats the patient when they first step into the office, how pleasant, organised and well put the building and the office is when the patient walks in, how appealing and attractive the decorations are (Shakaib U Rehman et al, 2005). Each exposure has the potential to either help the patient take the initiative to continue to make an appointment and follow through with the meeting, right through to how they interact and trust the doctor and their advice, too even deciding if they will not make an appointment and find another doctor (Shakaib U Rehman et al, 2005).

The first contact of the patient with the doctor is also important and the components that make this up include, if the doctor smiles or greats the patient in a friendly welcoming manner using good eye contact and eye contact, the vocal projection, vocal tone and the manner in which the doctor speaks to create report as well as directing the patient about the process of the appointment. The attire of the doctor and their appearance makes an impression and the office layout and appearance (Karen Sue, 2011).

When all of these components are achieved effectively the patient is much more likely to have a good first impression, which leads to them feeling more comfortable about the process, it helps them to open up and communicate more freely, as well as having a higher chance that the patient will trust and adhere to any advice and recommendations the doctor makes, which includes running test, making follow up appointments and adhering to any medical prescription plan that was set (Mary Klein Buller et al, 1987).

\section{Mannerisms and traits}

Another component of a good patient doctor is mannerism and traits of the person's involved (Piyush Ranjan et al, 2015). As mentioned above this can apply to the secretary or any other staff that is working 
for the doctor that the patient comes into contact with, however this will be describing the useful aspects of the mannerism and traits for a doctor (Raj Arora et al, 2004).

Beneficial mannerisms of a doctor include professionalism, how well the doctor is culturally aware of the patients' background, being polite and courteous, showing empathy and compassion when needed, being respectful to the patient, being open minded and non-judgemental when the patient disclose information, how effective the doctor is in establish trust and how supportive and understanding the doctor is of the patient's condition, choices and background story (Mary Klein Buller et al, 1987)

These characteristics can be worked on and improved, which in turn build a better foundation for establishing a healthy patient doctor relationship. It especially has a big impact on how willing the patient is in disclosing information and trusting that the doctor will keep their medical history confidential, as well as establishing a healthy patient's impression of the doctor's ability to help (Piyush Ranjan et al, 2015).

\section{Communication skills}

Communication skill makes a big component of establishing a good patient doctor relationship. Communication skills in this case is describing the doctor's ability to effectively communicate their thoughts, opinions and recommendations to the patient (Raj Arora et al, 2004). It comprises of many aspects, some of which are also components mentioned above which are also used to establish a good mannerism, like showing empathy, having good cultural awareness (Barbara M Korsch et al, 1968). However, this section will detail all of the aspects that are intimately linked with effective communication skills.

The first component is the verbal skills, which includes using language that the patient understands, speaking clearly and slowly with appropriate vocal tones to portray the message as well as showing appropriate emotions that is suitable for the situation (M Simpson et al, 1991).

Listening skills is another key component (M Simpson et al, 1991). This includes giving the patient time to talk and not cutting in, and understanding the important aspects that the patient informs the doctor (Barbara M Korsch et al, 1968).

Closely related to listening and communication skills are body language awareness and control, which includes body posture and position as well as facial expressions and subtle movements, which help to portray the doctor's emotions like empathy and cultural politeness, and establish compassion for the patient as well as showing an invested interest to helping the patient, which also builds on the trust and patient doctor relationship. It is also important for the doctor to be able to recognise the body language of the patient, such as recognising if they are open or if the patient is closed off and reserved or protective, as these are signs that show how the patient is feeling, which helps the doctor to understand why and through effective communication shills the emotional barriers can be uncovered and barriers of ineffective or unopen communication can be overcome (M Simpson et al, 1991).

Empathy is important in the medical field as patients are telling the doctors their deepest worries which they may not even feel comfortable telling their partners, hence it is important for the doctor to be able to express empathy in the correct time of the conversation, which is done through vocal tone, pace and body language and facial expressions addressed previously (Roger W Squier, 1990)

In terms of structure for gathering information and directing the appointment, the CalgaryCambridge guideline gives a good structure for the flow of the meeting, where it is focused on providing structure which helps creates efficiency and build a professional impression for the patient, as well as reducing the risk of leaving out anything important, and it also helps build a good patient doctor relationship (Suzanne M. Kurtz, 2002).

Additional helpful techniques for communication skills is to group information being given as well as asking similar questions together to help the doctor express what he needs to the patient as well as allowing the patient to better comprehend the process. An effective way of doing this is to physically say, we will be discussing $\mathrm{x}$ numbers of points, which are and then follow up and list the topics, and then using signpost, to mark the end and start of each topic. An example of this could be, I now want to ask about your family history, and proceed to ask relating questions about the family history (Suzanne 
M. Kurtz, 2002). This also give the patient awareness of what's to come and they can be ready and hence more likely to be open with the process.

To ensure that there is no communication misunderstanding, it is a good technique for the doctor to summarise what they learn from the interaction, which could be done at the end of the meeting, or at the end of each grouped topic of discussion. The patient should be given the chance to agree or clarify any misunderstandings (Suzanne M. Kurtz, 2002)

\section{Professional qualities}

The next quality discussed is professional qualities of the doctor (Peggy Wagner et al, 2007). Again this can and should also be applied to any employed staff that the doctor has which come into contact with patient such as the secretary (Peggy Wagner et al, 2007) Professional qualities allow for a good impression which help show that the doctor is well knowledge as well as maintaining trust as it helps the patient know that the doctor will not overcome any personal barriers (Jeanne M Farnan et al, 2013). It also helps build trust and establish good adherence to the doctor's recommendations (Lydia $S$ et al, 2008).

The components of professionalism include, knowing and adhering to professional boundaries in terms of what a doctor can and can't cross (Peggy Wagner et al, 2007). A good guide to this is the doctor's code of autonomy beneficent, non-maleficent as well as being ethical (Toni Suzuki et al, 2005). Also as mentioned previously the doctor's mannerism, body language, appearance, and good cultural awareness also plays a big part in establishing a good professionalism impression (Lydia S et al, 2008). Knowledge is also important and includes not just knowledge about medicine but about social interactions, the law and about the boundaries of a patient doctor relationship. It is also important to work with the patient and establish what they expect and working together to best achieve the patient's expectation through creating a treatment plan which considers the patient's needs, lifestyle and their chances of adhering to that plan, which will be elaborated on in the next point below (Donald $J$ et al, 2006). Also, the follow up arrangements and expectations also fall into this. An effective strategy is to set pre planned appointments before the patient leaves and have the secretary give the patient a reminder call before the appointment to remind the patient (Working Party of RCP, 2005). This should be used to follow up the patient and ensure that they are adhering to the treatment plan as well as addressing any complications that the patient might have (Peggy Wagner et al, 2007).

\section{Collaborative decision making}

Collaborative decision making is vital to ensure that you address the patient's needs, concerns and expectations (Lisa Maria et al, 2007). Knowing the patient's needs will help physicians understand if they are realistic or not and how to proceed (Donald J et al, 2006). Addressing any concerns will help the patient overcome any challenges and problems before they arise as well as improve adherence recommendations. Addressing unexpected expectations while achieving reasonable expectations will help patients trust the doctor and return for future appointments (Beth A Lown et al, 2009). These all work together to ensure the patient is satisfied with the treatment plan and uncover any problems if they are not so that they can be addressed and corrected (Jochanan Benbassat et al, 1998). In addition, the physical needs to consider the patient's past experience with adherence to a certain style of treatment regimen and any life factors that may affect their ability to adhere to any difficult regiment. If the treatment plan is not necessary then an alternative treatment plan should be agreed on by both parties which will help ensure that the patient has the best treatment possible according to their situation and lifestyles (Lisa Maria et al, 2007).

Each of the points addressed make up a small component of what builds a good patient doctor relationship, however collectively improving all aspects will yield the best results.

\section{Discussion}

Doctor patient relationship is an important and essential parts of the healthcare system. It is one of the key components that enable proper diagnosis and effective treatment, by ensuring trust and reliability from both sides. A patient walk into the hospital with the expectation that he/she will return cured and satisficed. It is a doctor's responsibility to uphold this expectation. In order for this to happen, 
a good doctor patient relationship must be established. Some major components of this relationship were discussed above. These components include first impressions, mannerism and traits of the doctor, commination skills, professional qualities and collaborative decision making. In order for a doctor to know the elements of a good doctor patient relationship, they must be given ample opportunities to cultivate these skills in medical school.

First impressions are often undermined and over looked. Recent studies have shown that things as insignificant as the doctor's dressing sense have a big impact on the patient's perception. For example, the doctor's attire can function as an effective tool of non-verbal communication in order to signal confidence, trust and empathy and establish a good patient-doctor relationship. (Heesu Chung et al, 2012) In another study, respondents overwhelmingly favor physicians in professional attire with a white coat. Wearing professional dress (ie, a white coat with more formal attire) while providing patient care by physicians may favorably influence trust and confidence-building in the medical encounter. (Shakaib $U$. Rehman et al, 2005) After getting through the first impression, another aspect that majorly effects the patients is the mannerism of the doctor. The physician's ability to remember them as a person and build up knowledge of their medical and personal preferences is one way that most patients said physicians maintained the comfortable relationship. (Nancy Pandhi et al, 2007) Previous research has reported that nonverbal elements of physician-patient communication influence medical outcomes such as patients' understanding, compliance, and saris/action with health care delivery. (Richard L. Street et al).

Communication is also one of the core skills that a doctor need. However almost nil training is provided for them to develop these skills. For example, in oncology, good communication with the patient is one of the most important aspects of treatment which a doctor could offer. It stabilizes the patient's mind and allows them enough trust and will power to fight against the disease. There have been studies conducted that show how ineffective communication brings complications in the patients. Inadequate communication may cause much distress for patients and their families, who often want considerably more information than is usually provided. Good communication can improve outcomes for patients and doctors, and deserves equal importance as developing clinical knowledge and procedural skill. The importance of good communication is so critical that Australian guidelines list effective communication as part of the required conduct for all doctors. Despite all the technological advances of recent decades, caring, compassionate, healing doctors remain the best therapeutic tool in medicine. The ability of a doctor to provide comfort through their presence and their words is a fundamental component of good medical care. (Warnecke E, 2014).

Involvement of the patient in decision making, regards treatment regimens and other matters that concern the patient is one of the basic rights of a patient and the fundamental duty of a doctor. Studies show that having a personal doctor-patient relationship was highly valued by patients and GPs, in particular for more serious, psychological and family issues. $77-88 \%$ of patients and $80-98 \%$ of GPs valued a personal relationship more than a convenient appointment. (K E Kearley et al, 2001).

\section{Conclusion}

There are a number of conflicting and varied information about what makes up a good patient doctor relationship. The varied information is in some way accurate however they are not a comprehensive overview of all of the factors and components which make up an effective patient doctor relationship.

This article discussed many points, summarizing them into five main focal areas; First impressions, mannerisms, communication skills, professionalism qualities, and collaborative decision making. They all help in their own way to improve the patient doctor relationship, however as evident in some overlapping, they do not work in isolation, but rather together in an intricate network which if all elements are well executed then that would produce the best patient doctor relationship. As in if a doctor was to implement one of these key points, they would improve their patient doctor relationship, however improving all aspects would have a significant impact.

This research and evaluation were written to be used to help guide a physician to evaluate their own practice and help identify areas of weakness which they could improve. 
Although this article was written to be a comprehensive overall guide on the subject, due to the vast nature and intricacies of human interaction, not all aspects could be documented and there may be further improvements to this formula.

To evaluate if this proposed structure is effective or not in improving a doctor's patient doctor relationship, there needs to be further research on its implication and results. Hence this article is a theoretical model only and has yet to be proven practically.

\section{Limitation}

The limitation of this research is the limited journals that was used. It would have been better to have a larger sample of journals used. In addition, some of the journals did not have research showing the effects of implementing such techniques, hence a confirmative effect of those recommendation can't be proven.

In regards to the limitation of this article, the advice is from a combination of a number of different journals, however there isn't any research done on the effectiveness on implementing these suggestions, and research should be done to validate the recommendations set out in this article. There may be unforeseen issues that might arise in a real-world research of implementing these recommendations.

\section{References}

[1]."A Comfortable Relationship: A Patient-derived Dimension of Ongoing Care" Family Medicine, April 2007. [2].Arora, Raj PhD; Singer, Joseph PhD; Arora, Alisha MD "Influence of Key Variables on the Patients' Choice of a Physician" Quality Management in Health Care: July-August-September 2004 - Volume 13 - Issue 3 - p 166173.

[3].Ball LE, Barnes KA, Crossland L, Nicholson C, Jackson C. "Questionnaires that measure the quality of relationships between patients and primary care providers: a systematic review".

[4].Barbara M. Korsch, Ethel K. Gozzi, Vida Francis "GAPS IN DOCTOR-PATIENT COMMUNICATION" Pediatrics November 1968, VOLUME 42 / ISSUE 5.

[5].Beth A. Lown MD Janice L. Hanson PhD EdS William D. Clark MD "Mutual influence in shared decision making: a collaborative study of patients and physicians" Health Expectations 18 May 2009.

[6].Carol Teutsch, MD Patient-Doctor Communication, Research gate.

[7].Cathy Charles, Amiram Gafni, Tim Whelan "Decision-making in the physician-patient encounter: revisiting the shared treatment decision making model" Social Science and Medicine Vol 49, Issue 5, September 1999.

[8].David C. Dugdale MD Ronald Epstein MD Steven Z. Pantilat MD "Time and the Patient-Physician Relationship" Journal of General Internal Medicine 25 December 2001.

[9].Donald J.Kiesler, Stephen M. Auerbach "Optimal matches of patient preferences for information, decisionmaking and interpersonal behavior: Evidence, models and interventions" Patient Education and Counseling Volume 61, Issue 3, June 2006, Pages 319-341.

[10]. Emanuel EJ, Emanuel LL. "Four Models of the Physician-Patient Relationship" JAMA. 1992;267(16):22212226. doi:10.1001/jama.1992.03480160079038.

[11]. Gallagher TH, Levinson W. "A prescription for protecting the doctor-patient relationship."

[12]. Guseh JS, Brendel RW, Brendel DH "Medical professionalism in the age of online social networking" Journal of Medical Ethics 2009;35:584-586.

[13]. Heesu Chung, Hyeyeon Lee, Dong-Seon Chang, Ho-Sun Kim, Hyejung Lee, Hi-Joon Park, Younbyoung Chae "Doctor's attire influences perceived empathy in the patient-doctor relationship" Patient Education and Counseling Volume 89, Issue 3, December 2012.

[14]. Jeanne M. Farnan, MD, MHPE; Lois Snyder Sulmasy, JD; Brooke K. Worster, MD; Humayun J. Chaudhry, DO, MS, SM; Janelle A. Rhyne, MD, MA; Vineet M. Arora, MD, MAPP "Online Medical Professionalism: Patient and Public Relationships: Policy Statement From the American College of Physicians and the Federation of State Medical Boards" Annals of Internal Medicine 13 April, 2013.

[15]. Jennifer Fong Ha, MBBS (Hons) Dip Surg Anat and Nancy Longnecker, PhD "Doctor-Patient Communication: A Review". 
[16]. Jochanan Benbassat MD, Dina Pilpel PhD \& Meira Tidhar MSc (1998) "Patients' Preferences for Participation in Clinical Decision Making: A Review of Published Surveys", Behavioral Medicine, 24:2, 81-88, DOI: $10.1080 / 08964289809596384$.

[17]. K E Kearley, G K Freeman and A Heath "An exploration of the value of the personal doctor-patient relationship in general practice”. Br J Gen Pract 2001; 51 (470): 712-718.

[18]. Karen Sue Schaepe "Bad news and first impressions: Patient and family caregiver accounts of learning the cancer diagnosis” Social Science \& Medicine Volume 73, Issue 6, September 2011, Pages 912-921.

[19]. Kelley JM, Kraft-Todd G, Schapira L, Kossowsky J, Riess H (2014). "The influence of the patient-clinician relationship on healthcare outcomes: a systematic review and meta-analysis of randomized controlled trials". PLOS ONE. 9 (4): e94207.

[20]. Levinson W, Roter D. The effects of two continuing medical education programs on communication skills of practicing primary care physicians. J Gen Intern Med. 1993; 8:318-24. [PubMed].

[21]. Lisa Maria E. Frantsve, Robert D. Kerns; "Patient-Provider Interactions in the Management of Chronic Pain: Current Findings within the Context of Shared Medical Decision Making” Pain Medicine, Volume 8, Issue 1, 1 January 2007, Pages 25-35.

[22]. Lydia S. Dugdale and Mark Siegler and David T. Rubin. "Medical Professionalism and the Doctor-Patient Relationship." Perspectives in Biology and Medicine 51, no. 4 (2008): 547-553.

[23]. M Simpson, R Buckman, M Stewart, P Maguire, M Lipkin, D Novack, and J Till "Doctor-patient communication: the Toronto consensus statement." BMJ. 1991 Nov 30; 303(6814): 1385-1387.

[24]. Mary Klein Buller and David B. Buller "Physicians' Communication Style and Patient Satisfaction" Journal of Health and Social Behavior Vol. 28, No. 4 (Dec., 1987), pp. 375-388.

[25]. Mechanic D, Schlesinger M. The impact of managed care on patients' trust in medical care and their physicians. JAMA. 1996;275(21):1693-7. [PubMed].

[26]. Nadelson, T. (1971) 'Emotional Interactions of Patient and Staff: A Focus of Psychiatric Consultation', Psychiatry in Medicine, 2(3), pp. 240-246. doi: 10.2190/GPAW-0XRM-C4J4-KTT1.

[27]. Nancy Pandhi, MD, MPH; Barbara Bowers, RN, PhD; Fang-pei Chen, MSW, PhD.

[28]. Paul Haidet Joyce E Dains Debora A Paterniti Laura Hechtel Tai Chang Ellen Tseng John C Rogers Medical student attitudes toward the doctor-patient relationship.

[29]. Peggy Wagner Julia Hendrich Ginger Moseley Valera Hudson "Defining medical professionalism: a qualitative study" 20 February 2007.

[30]. Piyush Ranjan, Archana Kumari, and Avinash Chakrawarty "How can Doctors Improve their Communication Skills?” 2015 Mar 1. doi: 10.7860/JCDR/2015/12072.5712.

[31]. RICHARD L. STREET Jr. DAVID B. BULLER Patients' Characteristics Affecting Physician-Patient Nonverbal Communication Human Communication Reseearch September 1988.

[32]. Roger W.Squier "A model of empathic understanding and adherence to treatment regimens in practitionerpatient relationships" Social Science \& Medicine Volume 30, Issue 3, 1990, Pages 325-339.

[33]. Sadati AK, Tabei SZ, Lankarani KB. "A Qualitative Study on the Importance and Value of Doctor-Patient Relationship in Iran: Physicians' Views.”.

[34]. Shakaib U. Rehman MD, Paul J. Nietert PhD, Dennis W. Cope MD, Anne Osborne Kilpatrick DPA "What to wear today? Effect of doctor's attire on the trust and confidence of patients" The American Journal of Medicine Volume 118, Issue 11, November 2005, Pages 1279-1286.

[35]. Shakaib U. Rehman MD, Paul J. Nietert PhD, Dennis W. Cope MD, Anne Osborne Kilpatrick DPA "What to wear today? Effect of doctor's attire on the trust and confidence of patients" The American Journal of Medicine Volume 118, Issue 11, November 2005, Pages 1279-1286.

[36]. 36. Susan Dorr Goold, MD, MHSA, MA and Mack Lipkin, Jr., MD "The Doctor-Patient Relationship: Challenges, Opportunities, and Strategies".

[37]. Suzanne M. Kurtz "Doctor-Patient Communication: Principles and Practices” Volume 29, Issue S2 (A PeerReviewed Supplement to the Canadian Journal of Neurological Sciences) 2002 , pp. S23-S29.

[38]. Swenson, S.L., Buell, S., Zettler, P. et al. J GEN INTERN MED (2004) 19: 1069.

[39]. The Social Medicine Reader: edited by Gail Henderson, Nancy M. P. King, Ronald P. Strauss, Sue E. Estroff [40]. Toni Suzuki Laidlaw, David M Kaufman, Heather MacLeod, Sander Van Zanten, David Simpson, William Wrixon "Relationship of resident characteristics, attitudes, prior training and clinical knowledge to communication skills performance" 21 December 2005. 
[41]. Warnecke E "The art of communication”. Aust Fam Physician. 2014 Mar;43(3):156-8.

[42]. William Clark, MD, Mack Lipkin, MD, Howard Graman, MD, and Jeannette Shorey, MD "Improving Physicians' Relationships with Patients".

[43]. Woolf Steven H, Grol Richard, Hutchinson Allen, Eccles Martin, Grimshaw Jeremy. "Potential benefits, limitations, and harms of clinical guidelines" BMJ 1999.

[44]. Working Party of the Royal College of Physicians. "Doctors in society. Medical professionalism in a changing world” Clin Med (Lond). 2005 Nov-Dec;5(6 Suppl 1):S5-40. 